\title{
O BRINQUEDO COMO FOMENTADOR DAS CULTURAS DA INFÂNCIA NO CONTEXTO ESCOLAR
}

Larissa Aparecida Trindade dos Santos

Faculdade de Presidente Prudente - FAPEPE, Curso de Educação Física. E-mail: larissatrindadepef@yahoo.com.br Financiamento da FAPESP

\section{RESUMO}

O presente artigo traz resultados de uma pesquisa de mestrado, desenvolvida junto ao Programa de Pós-Graduação em Educação da Faculdade de Ciências e Tecnologia - UNESP, Campus de Presidente Prudente, financiada pela FAPESP, que estabeleceu como objetivo central compreender como o brinquedo vem sendo utilizado no contexto de instituições educacionais infantis. Para tal, adotou uma metodologia de natureza qualitativa, do tipo descritivo-interpretativa e empregou instrumentos metodológicos de observação, entrevista semiestruturada e análises bibliográficas. A pesquisa ancorada na Sociologia da Infância apresentou, dentre os seus resultados, que os professores das instituições investigadas empregavam o brinquedo de forma reducionista, apenas como material para ensinar conteúdos e habilidades específicos ou, ainda, como recurso para atrair e distrair as crianças, desvalorizando assim o potencial cultural e histórico desse objeto educativo.

Palavras-Chave: Brinquedo; Criança; Cultura; Sociologia da Infância; Práticas educativas.

\section{THE TOY AS DEVELOPER OF CHILDHOOD CULTURES IN THE SCHOOL CONTEXT}

\begin{abstract}
This article presents results of a master's research, conducted at the Graduate Program in the Faculty of Education Science and Technology - UNESP, Presidente Prudente Campus, funded by FAPESP, which has set as its main objective to understand how the toy has been used in the context of children's educational institutions. To this end, it adopted a methodology of qualitative, descriptive-interpretative type and employed methodological tools: observation, semi-structured interviews and bibliographic analysis. The research anchored in the sociology of childhood presented, from the results, that teachers of institutions investigated employing the toy reductionist way, just as material for teaching specific content and skills or even as a resource to attract and entertain children as well devaluing the cultural and historical potential this educational object.
\end{abstract}

Keywords: Toy; Child; Culture; Sociology of childhood; Educational practices. 
INTRODUÇÃO

A Sociologia da Infância é um campo teórico recente, que se constituiu e ganhou destaque na França com os estudos de Sirota e, na Inglaterra, com os estudos de Montandon. De acordo com Montandon (2001), somente a partir dos anos 80 do século XX alguns sociólogos começaram a se interessar pelos estudos da infância devido às carências encontradas sobre esse objeto de estudo. Anteriormente a este período, a infância era vista paralelamente aos estudos da família e da educação, portanto, não se configurava como um ramo particular da Sociologia.

Sarmento (2008) aponta que a investigação sobre a infância em si mesma e a sua conceituação enquanto uma categoria geracional específica é bastante atual. Sendo assim, revela que o seu papel principal é o de estudar a infância, refletir sobre a realidade social como um todo e apresentar concepções de crianças e de educação distintas das vertentes tradicionais como as durkheimianas, que encaravam as crianças como protótipos de adultos.

Montandon (2001) complementa dizendo a intenção dos atuais sociólogos da infância é estudar com maior profundidade as crianças e os seus contextos, partindo de suas ações e falas, as quais foram negligenciadas durante séculos, além de garantir, seus direitos como cidadãs.
Segundo essa abordagem teórica, todos os sujeitos são atores sociais, inclusive as crianças, as quais reconfiguram os saberes transmitidos pelos adultos de uma maneira particular, edificando, assim, uma cultura própria, a cultura infantil. Corsaro (2009), nessa direção, apresenta o conceito de reprodução interpretativa, que define a capacidade das crianças de interpretar as situações e os conhecimentos com os quais entram em contato, reproduzindo significados próprios que lhes fazem sentido.

Sarmento (2002), ancorado em Buckinghan (1994, 2000) e Pinto (2000), enfatiza que as crianças não são receptoras passivas desses produtos, muito pelo contrário, elas estabelecem com esses objetos culturais relações interpretativas, críticas e criativas.

A Sociologia da Infância destaca, então, a relevância dos brinquedos e brincadeiras como recursos fundamentais para a interpretação do mundo adulto, da formação da cultura de pares e do desenvolvimento infantil. Como salienta Corsaro (2005, p.8): “o jogo de papéis implica mais do que aprender conhecimento social específico; ele envolve também aprender acerca das relações entre contexto e comportamento" e ainda ressignificar esses elementos, produzindo uma cultura infantil própria, a qual é transmitida aos seus coetâneos.

Todas essas características infantis nos revelam seus modos de ver, viver $\mathrm{e}$ 
compreender o mundo distintamente dos adultos. Complementando as singularidades do universo infantil, Sarmento (2004) apresenta os quatro eixos considerados como estruturadores das culturas da infância que, segundo o autor, correspondem à capacidade infantil de construir de forma sistematizada modos de ação intencional e de significação do mundo, que são a interatividade, a ludicidade, a fantasia do real e a reiteração.

Dessa maneira, destacamos a relevância da proposição de atividades lúdicas e o uso dos brinquedos no ambiente educativo, como elementos que possibilitam coletar informações sobre as crianças, seus interesses, gostos e angústias e a partir dos quais é possível propiciar situações que façam sentido à criança e promovam o seu desenvolvimento social, emocional, cognitivo e motor.

A Sociologia da Infância é, em suma, um ramo da Sociologia que estuda a criança e suas singularidades, seus modos de interação e incorporação da cultura. Luta, ainda, pela garantia dos direitos infantis, ao conceber as crianças como cidadãos completos, agentes de sua formação individual e social. As escolas da infância, de acordo com essa vertente, devem ser ambientes ricos em oportunidades e que, sobretudo, respeitem os interesses e as particularidades das crianças. O brincar e o brinquedo, nessa perspectiva teórica, são considerados elementos próprios da cultura infantil, os quais são fundamentais para os processos de socialização, expressão, comunicação, produção cultural e autoorganização. Nesta pesquisa tivemos como objetivo principal "identificar o uso do brinquedo como fomentador do desenvolvimento e das culturas infantis" e, para tanto, adotamos o eixo ludicidade como referência e o brinquedo como objeto de estudo central. Consideramos como pressuposto básico que o brinquedo é um objeto cultural que carrega em sua essência aspectos sociais, econômicos e políticos, o qual permite verificar, inclusive, as visões de criança e de infância de uma determinada sociedade.

\section{METODOLOGIA}

Esta investigação caracteriza-se como uma pesquisa de natureza qualitativa, do tipo descritivo-interpretativa, por considerar que a descrição das características do grupo pesquisado e do contexto contribui para explicitar o problema da pesquisa e, ao mesmo tempo, permite analisar e compreender como o brinquedo é empregado no contexto da Educação Infantil.

Os procedimentos metodológicos adotados foram: análise bibliográfica, observação e entrevista semiestruturada.

Tais procedimentos foram necessários para a resolução dos objetivos da pesquisa, a saber: diagnosticar o tipo, a frequência, o modo e a finalidade do uso do brinquedo nas práticas educativas; verificar quais as 
concepções de brincar, de criança e de Educação Infantil que norteiam as práticas dos professores investigados; e, ainda, por meio da observação das crianças nas instituições pesquisadas durante diversas situações lúdicas, compreender a importância e o valor/sentido do brinquedo para essa categoria social.

A observação foi empregada no intuito de acompanhar a prática dos professores investigados em sala de aula, para sentir o contexto e as relações que se dão dentro dele, de forma a registrar essa vivência e socializar com os atores os resultados prévios obtidos. Já a entrevista foi utilizada por possibilitar a coleta de dados de forma imediata, além de permitir o aprofundamento e a discussão de informações consideradas mais complexas e confidenciais. Optamos, nesta investigação, entre outras possibilidades, pela entrevista semiestruturada, considerando que esta "se desenrola a partir de um esquema básico, porém não aplicado rigidamente, permitindo que o entrevistador faça as necessárias adaptações" (LUDKE; ANDRÉ, 1986, p. 34). Esse tipo de entrevista permite então, colher dos investigados informações mais detalhadas e mais próximas da realidade, as quais ainda trazem embutidas suas interpretações e concepções de mundo.

Após o recebimento da autorização do Comitê de Ética (291/2008) para o desenvolvimento da pesquisa in loco. As duas instituições escolares infantis foram escolhidas devido à adesão de uma proposta pedagógica de integração entre escola e universidade estando, dessa forma, abertas à pesquisa e à proposição de melhorias educacionais fundadas em dados científicos.

\section{RESULTADOS DA PESQUISA}

Os resultados da pesquisa apontam que os brinquedos, embora fossem utilizados quase todos os dias nos ambientes educativos, não eram encarados como elementos promotores da cultura e do desenvolvimento infantil. Dessa forma, eram empregados de maneira reducionista, apenas como meio de ocupação do tempo das crianças em situações não sistematizadas ou, ainda, como suporte para o ensino de conteúdos específicos, empobrecendo, desse modo, o valor educativo, cultural do brinquedo, conforme destacam, igualmente, em suas pesquisas, Kishimoto (2001) e Mora (2006). Além disso, constatamos que os brinquedos mais empregados nos contextos educativos investigados eram aqueles relacionados à aprendizagem de seriação, classificação, construção e leitura de palavras e identificação de números. Notamos, sobretudo, uma precariedade de objetos lúdicos que trabalhem a capacidade imaginativa, corporal, social e criativa das crianças, especialmente nos agrupamentos pré-escolares, nos quais as crianças, na maioria das vezes, só têm direito de brincar após o término das tarefas propostas pelos 
professores. Os grupamentos do Berçário I e II e Maternal já dispunham de uma variedade maior de brinquedos de cunho imaginativo, dentre eles, fantoches e bichos de pelúcia. Nessas turmas, embora o brinquedo e o brincar fossem oferecidos com mais frequência do que nas salas de Pré-escola, as finalidades educativas também podem ser ampliadas, haja vista, que os materiais, na maioria das vezes eram disponibilizados para o brincar livre, sem a mediação do adulto.

Nessa direção, observamos que nos grupamentos de 0 a 3 anos, o contexto educativo priorizava aspectos como a higiene, o sono e a alimentação (cuidados básicos) e, em menor proporção, o desenvolvimento de habilidades e capacidades humanas, apresentando, por vezes, um caráter no qual predomina a proteção. Nos grupos préescolares, o espaço pedagógico valorizava, predominantemente, o disciplinamento, o silêncio, a imobilidade, com investimento na alfabetização de algumas linguagens como a oral, a escrita e a matemática, em detrimento das demais formas de expressão, transformando as instituições de Educação Infantil em ambientes compensatórios. Já as visões de Educação Infantil, detectadas junto à maioria das professoras investigadas perpassavam pelo viés assistencialista (turmas dos Berçários e Maternal) e propedêutico (turmas da Pré-escola).

A concepção dominante de criança, em ambas as instituições infantis, é a de adulto em miniatura, de crianças que têm que se adequar às normas escolares, adotar novas posturas, esquecer seus desejos e características peculiares. Desse modo, são vistas como sujeitos que não podem usufruir de seus direitos e identidades culturais.

\section{DISCUSSÃO}

O contexto relatado acima são resquícios de um processo histórico da Educação Infantil no mundo e no Brasil, o qual Kuhlmann Júnior (1998) assevera que foi fortemente marcado pelo caráter assistencialista, beneficente, sem fins educativos, cujo objetivo principal dessas instituições era visar à obediência e à retirada das crianças da rua, pois esse era considerado um ambiente deformador (princípio higienista), além disso, assegurar às crianças a saúde do corpo e adaptá-las aos moldes da sociedade vigente. Os filhos dos ricos, contudo, recebiam atendimento nos jardim de infância, os quais tinham caráter educacional, de preparação para a escola.

Desse modo, portanto, notamos que muitos problemas encontrados atualmente nas instituições de Educação Infantil são decorrentes de uma história de educação caracterizada pela discriminação, submissão, descaso, negligência e interesses ideológicos dominantes, que sempre privilegiaram os ricos e seus filhos e humilharam e desprezaram os pobres, os trabalhadores. 
Apoiados em Müller e Redin (2007), ressaltamos que as entidades de educação infantil para a Sociologia da Infância apresentam como papel principal oferecer um espaço interativo e participativo, no qual as crianças tenham contato com a cultura e os pares, enriquecendo, assim, o seu processo de aprendizagem e desenvolvimento que as instituições de Educação Infantil devem ser espaços ricos, que valorizem a ludicidade, a interação, a participação e os olhares das crianças sobre o mundo. $E$ que respeitem as suas realidades e diferenças, tomando-as como suporte para o planejamento e a proposição de atividades e propiciem às crianças acesso, ampliação do repertório cultural humano e o seu desenvolvimento global.

O brinquedo e a brincadeira, desse modo, apresentam-se como elementos culturais fomentadores da aprendizagem e do desenvolvimento infantil. Conforme destaca Corsaro (2009), são nesses momentos que as crianças podem interagir com seus pares, trocar objetos, hábitos, informações sobre jogos e regras, enriquecendo suas aprendizagens e colaborando para a conservação e renovação do repertório cultural de uma sociedade.

De acordo com Ferreira (2004), a Sociologia da Infância, concebe brinquedo e brincadeira como recursos privilegiados para conhecer as crianças e compreender as suas infâncias, haja vista que as crianças os utilizam como meio para se comunicar com a cultura e com os sujeitos, entendendo a realidade a sua volta.

Ao ouvir ou ler as explicações dadas pelas professoras com relação à escassez com que são empregados o brinquedo e a brincadeira no contexto pedagógico, acreditamos que se fundamentam, sobretudo, em três aspectos: na pressão exercida sobre os professores pelas Secretarias Municipais de Educação e pelos pais, os quais exigem dos docentes a alfabetização das crianças da Educação Infantil; na falta de conhecimento sobre o universo lúdico, oriunda de processos de formação inicial e continuada deficitários; e/ou, ainda, nas dificuldades em trabalhar com essas ferramentas educativas.

Ressaltamos, entretanto, que mesmo que essas cobranças existam e não duvidamos disso, elas não são os únicos motivos pelos quais os brinquedos e as brincadeiras não recebem tratamentos e usos adequados, pois em diversas situações presenciamos, por parte dos professores, uma falta de compreensão sobre o universo infantil, além de falta de paciência, motivação, bom senso, flexibilidade e tolerância para desenvolver essas atividades junto às crianças.

O cenário apresentado nos revela que alguns aspectos ainda precisam ser melhorados no contexto das instituições educativas estudadas e um deles consiste na forma e na finalidade com que o brinquedo é utilizado na prática pedagógica, uma vez que 
somente o seu uso não garante a qualidade da atividade e, muito menos, a aprendizagem da criança. Vários critérios devem ser levados em consideração para que a riqueza desse material seja explorada, resultando, assim, em possibilidade de conhecimento e desenvolvimento para a criança.

Outro elemento que precisa ser revisto no âmbito da educação infantil é a visão de criança, que deve ultrapassar a vertente de adulto em miniatura e de sujeito passivo, pois segundo Prout e James apud Sarmento (2008, p.24) "as crianças são e devem ser vistas como atores na construção e determinação das suas próprias vidas sociais, das vidas dos que as rodeiam e das sociedades em que vivem. As crianças não são sujeitos passivos de estruturas e processos sociais". Portanto, precisam ser encaradas como sujeitos competentes, protagonistas de seus processos de interação e formação, os quais atuam e interpretam o contexto vivido por meio de modos peculiares, distintos dos adultos.

\section{CONSIDERAÇÕES FINAIS}

Embasados na Sociologia da Infância e nos documentos legais brasileiros relacionados à educação para a infância, salientamos que as instituições de Educação Infantil devem ser espaços ricos, que valorizem a ludicidade, a interação, a participação e os olhares das crianças sobre o mundo. E que respeitem as suas realidades e diferenças, tomando-as como suporte para o planejamento e a proposição de atividades e propiciem às crianças acesso, ampliação do repertório cultural humano e $\mathrm{o}$ seu desenvolvimento global.

Conforme aponta a Sociologia da infância, as atividades lúdicas, nas etapas iniciais do desenvolvimento da criança, possibilitam momentos privilegiados para se conhecer melhor as crianças e para obter informações que podem ser utilizadas durante o planejamento, a execução e a avaliação das atividades pedagógicas, proporcionando avanços significativos no processo de formação das crianças.

Destacamos ainda que, para a organização de contextos educativos e a execução de práticas pedagógicas de qualidade é necessário conhecer profundamente a criança, compreender como ela interage, aprende e apropria-se dos elementos de uma determinada cultura, tratála como ator social e valorizar as suas culturas.

Portanto, os profissionais e instituições de educação infantil que levam em consideração os aspectos acima mencionados e revelam concepções, amparadas nos avanços científicos mais atuais sobre criança, educação para a infância, brincar e brinquedos, certamente oferecerão às crianças propostas educativas mais significativas e ambientes educativos mais ricos e colaboradores no processo de formação infantil. 


\section{REFERÊNCIAS}

CORSARO. W. A. Acção colectiva e agência nas culturas de pares infantis. Indiana, USA: University, Bloomington, 2005.

.Reprodução interpretativa e cultura de pares. In: MÜLLER, F.; CARVALHO, A. M. A. Teoria e prática na pesquisa com crianças Diálogos com William Corsaro. São Paulo: Cortez, 2009, p. 31-50.

PEREIRA, R. S. O lúdico e a constituição de sujeitos no cotidiano de uma escola de educação infantil. 2008. 215f. Dissertação (Mestrado em Educação) - Faculdade de Educação da Universidade federal de Uberlândia- UFU.Uberlândia, MG.

KISHIMOTO, T. M. Brinquedo e materiais pedagógicos nas escolas infantis. Educação e Pesquisa, São Paulo, v. 27, n.2, jul./dez.,2001.

KUHLMANN JUNIOR, M. Infância e educação Infantil: uma abordagem histórica. Porto Alegre: Mediação, 1998. 210p.

LUDKE, M.; ANDRÉ, M. E. D. A. Pesquisa em educação: abordagens qualitativas. São Paulo: EPU, 1986.

MONTANDON, C. Sociologia da infância: balanço dos trabalhos em língua inglesa. Cadernos de Pesquisa, n. 112, p.33-60, mar., 2001.

MORA, A.P. Design de Brinquedos: estudo dos brinquedos utilizados nos centros de Educação Infantil do município de São Paulo. 2006. 153f. Dissertação (Mestrado em Design e Arquitetura) - Faculdade de Arquitetura e Urbanismo da Universidade de São Paulo, São Paulo.

MÜLLER, F.; REDIN, M. Sobre as crianças, a infância e as práticas escolares. In: REDIN, E; MULLER, F; REDIN, M. M (orgs.). Infâncias idades e escolas amigas das crianças. Porto alegre:, Mediação, 2007. p.11-22.
SARMENTO, J. M; CERISARA, A. B. Crianças e Miúdos- perspectivas sociopedagógicas da infância e educação. Porto-Portugal: ASA editores, 2004.

SARMENTO, J. M. Sociologia da Infância: Correntes e confluências. In: SARMENTO, $M$. J.; GOUVEA, M. C. S. (orgs.). Estudos da infância- educação e práticas sociais. Petrópolis, RJ: Vozes, 2008, p.17-49. Imaginários e culturas da infância. Instituto de estudos da infância, 2002, 18p. Disponívelem: $<$ http://titosena.fortunecity.com/Arquivos/Art igos infancia/Culturanalnfancia.pdf $>$. Acesso em: 02 jul. 2010.

Recebido para publicação em 19/08/2015 Revisado em 08/09/2015 Aceito em 09/09/2015 